\title{
Can a physical activity similar to activities of daily living cause dynamic hyperinflation and change the thoracoabdominal configuration in patients with chronic obstructive pulmonary disease?
}

This article was published in the following Dove Press journal:

International Journal of Chronic Obstructive Pulmonary Disease

\author{
Aldenice Magalhães Capeletti (D) \\ Adriana do Carmo \\ Santos Sousa (iD) \\ Carla Lima Feitoza (iD) \\ Renata Pedrolongo Basso- \\ Vanelli (iD ${ }^{2}$ \\ Evelim LFD Gomes (D) \\ Dirceu Costa (D) \\ 'Rehabilitation Sciences Program, \\ UNINOVE, São Paulo, Brazil; \\ ${ }^{2}$ Spirometry and Respiratory \\ Physiotherapy Laboratory - LEFiR, \\ Universidade Federal de São Carlos - \\ UFSCar, São Carlos, São Paulo, Brazil
}

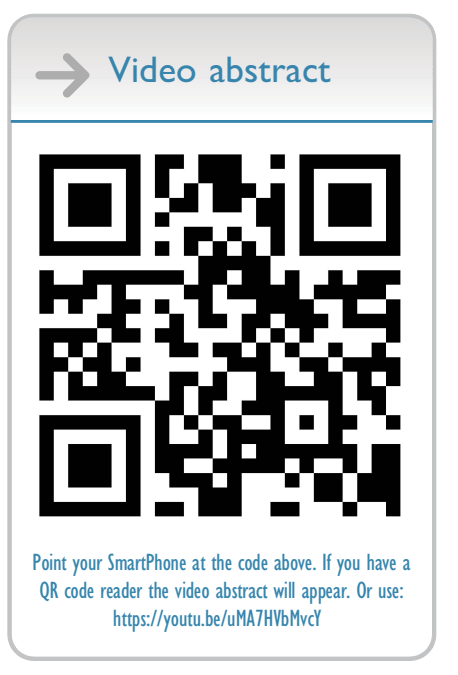

Correspondence: Dirceu Costa Rehabilitation Sciences Program, UNINOVE, LARESP 235/249 Vergueiro Street, Liberdade, São Paulo 01504-00I, Brazil

Tel +5 5II 3665987

Email dcosta@uni9.pro.br
Introduction: COPD is characterized by the ventilatory limitation, with reduction of the inspiratory reserve volume and dynamic hyperinflation (DH), which changes the configuration of the thoracic compartment, resulting in a disadvantage in respiratory muscle kinetics, and reduced functional capacity. The optoelectronic plethysmography (OEP) has been used to monitor changes in thoracoabdominal mobility. The Glittre-ADL test is a short battery of functional tests that simulate activities of daily living. In mild and moderate COPD, the effect of Glittre-ADL on thoracoabdominal kinetics and DH is understudied.

Objective: The aim of our study was to evaluate the acute effects of the Glittre-ADL test on lung function and thoracoabdominal mobility using OEP in patients with mild and moderate COPD.

Materials and methods: Twenty-five male and female patients between 45 and 80 years of age with COPD were submitted to the exercises that simulated Glittre-ADL test. Spirometry and OEP were performed before and after the test.

Results: After the Glittre test, increases were found in EV $(p=0.005)$, percentage of contribution of the abdominal compartment $(p=0.054)$ and expiratory reserve volume (ERV) $(p=0.006)$ and reductions were found in the contribution of the upper thoracic compartment $(p=0.008)$ and inspiratory capacity (IC) $(p=0.040)$.

Conclusion: The acute effect of ADL was a change in thoracoabdominal kinetics, especially the percentage of contribution of the abdominal compartment, as demonstrated by OEP. These findings, together with the reduction in IC and increase in ERV, after the GlittreADL test suggest the occurrence of $\mathrm{DH}$, even in patients with mild to moderate COPD according to the GOLD classification.

Keywords: COPD, dynamic hyperinflation, plethysmography

\section{Introduction}

COPD is characterized by the persistent obstruction of airflow, caused by a chronic inflammatory response of the airways and lungs to harmful agents or gases. ${ }^{1}$ Ventilatory limitation increase as the disease progresses, that involves the worsening of dyspnea, with reductions in functional capacity and quality of life. ${ }^{2}$

This ventilatory limitation is characterized by reduction of the inspiratory reserve volume and dynamic hyperinflation $(\mathrm{DH})$, which changes the configuration of the thoracic compartment, with increases in both the lateral and anteroposterior 
diameters, resulting in a disadvantage in respiratory muscle kinetics, with a consequent reduction in the strength and endurance of these muscles. ${ }^{3,4}$ With $\mathrm{DH}$, the diaphragm is shifted downwards, which results in a reduction in the apposition zone, making it incapable of generating pressure. In the long term, the fibers of the diaphragm undergo adaptations, with loss of sarcomeres, atrophy and alteration of the fiber type. ${ }^{5}$

Conventional spirometric evaluations, such as airflow measures, do not always detect $\mathrm{DH}$ or changes in the thoracoabdominal kinetics. ${ }^{5,6}$ An exercise-induced reduction in inspiratory capacity (IC) has been used to monitor DH. ${ }^{7,8}$ Moreover, optoelectronic plethysmography (OEP) has been used to monitor changes in thoracoabdominal mobility. OEP enables measuring changes in the total volume of the thoracic wall and different compartments (upper thoracic, lower thoracic and abdominal) through optic measurements of points positioned on the outer surface of the thoracic wall. ${ }^{9}$

The Glittre-ADL test is a short battery of functional tests that simulate activities of daily living. It was developed and validated specifically for patients with COPD and involves a set of tasks, such as sitting down and standing up from a chair, going up and down stairs, squatting, moving objects with the upper limbs and walking on a flat surface. ${ }^{10-12}$ In mild and moderate COPD, the effect of Glittre-ADL on thoracoabdominal kinetics and $\mathrm{DH}$ is understudied. We hypothesized that Glittre-ADL causes thoracoabdominal changes and increases $\mathrm{DH}$.

The aim of our study was to evaluate the acute effects of the Glittre-ADL test on lung function and thoracoabdominal mobility using OEP in patients with mild and moderate COPD.

\section{Materials and methods}

This cross-sectional study was developed at the Biodynamic Analysis Laboratory and the Human Movement Laboratory of University Nove de Julho involving patients with COPD, both gender, aged 45-80 years. This study received approval from the Human Research Ethics Committee of the University (certificate numbers: 2.590.186 and 84731818.7.0000.5511) and all participants provided written informed consent, and that this study was conducted in accordance with the Declaration of Helsinki.

The inclusion criteria consisted of patients over 40-85 years of age, of both genders, with a diagnosis of COPD, performed by clinical history plus confirmation given by the presence of airflow obstruction in post-bronchodilator spirometry. They should show clinical stability, that is, the absence of exacerbation 3 months before the evaluation. Under pharmacological treatment patients were included in prolonged home oxygen therapy. Exclusion criteria were patients with asthma or other diagnosis of respiratory disease, inability to perform functional capacity tests (arthrosis, visual impairment, stroke sequelae and amputees) post-myocardial infarction with 4 months before the start of the study, unstable angina, arrhythmias or congestive heart failure classes III and IV.

\section{Procedures}

After a complete anamnesis, the individuals were submitted to a spirometric test, which consisted of inspiratory and expiratory maneuvers using a previously calibrated spirometer (Easy-One NDD, ${ }^{\circledR}$ Medizintechnik, Switzerland). Three reproducible maneuvers were performed according to recommendations of the American Thoracic Society. ${ }^{13}$ All tests were performed in a climate-controlled environment. The following measures were determined: FVC, $\mathrm{FEV}_{1}$, the $\mathrm{FEV}_{1} / \mathrm{FVC}$ ratio and maximum voluntary ventilation. The values obtained were reported in relation to the predicted values for Brazilian adults ${ }^{14}$

The evaluation of static thoracic volumes was performed using OEP (OEP System, BTS, Italy). For such, 89 adhesive reflective markers were placed on the thorax and abdomen of the participants, who remained seated on a standardized bench with no support for the trunk. Thoracoabdominal movements were captured at a calibration frequency of $60 \mathrm{~Hz}$ by four cameras behind and four cameras in front of the volunteer during normal quiet breathing. Each reading lasted $40 \mathrm{~s}$ and was processed using the "Quiet Breathing" protocol of the Smart Capture software program.

With these characteristics, it was possible to measure the percentage contribution of the three compartments previously established by the OEP system, namely: upper thoracic compartment, lower thoracic and abdominal. Data were processed from specific programs (OEP analyzer, OEP tracker, smart analyzer) and were transformed into numerical values in an Excel spreadsheet to obtain the variables.

The OEP readings were performed at rest and immediately after the ADL exercises. ${ }^{9,15}$ The Glittre-ADL test evaluated the functional capacity of COPD patients, involves rising from a chair, lifting, carrying and bending, activities that are designed to represent common activities in everyday life. The patients desenvolved the exercise 
with backpack contained a weight of $2.5 \mathrm{~kg}$ for women and $5 \mathrm{~kg}$ for men. ${ }^{11,12}$ However, in this study the GlittreADL test was adapted with the backpack commonly placed on the back during the test positioned at the height of the iliac crest in order not to interfere with the markers placed on the thorax and abdomen (Figure 1). ${ }^{11,12,16,17}$

Before and after completing the Glittre-ADL test, the sensations of dyspnea and fatigue of the lower limbs were assessed by the Borg CR 10 scale. $^{12}$ The criteria for interrupting the test were dyspnea, dizziness, chest pain, a drop in oxygen saturation $\left(\mathrm{SpO}_{2}\right)$ below $85 \%$ or an increase in heart rate (HR) to $>90 \%$ maximum HR, determined using the formula proposed by Karvonen. ${ }^{8}$

The main parameter was the total time required to complete the test, calculated according to the equation described by Reis $181.558+(0.018 \times \mathrm{BMI})+(0.016 \times$ age years). Two tests were performed, but the second test was used for analysis, due to the learning effect reported in the literature. ${ }^{17}$

\section{Statistical analysis}

The SPSS statistical package (SPSS Statistics version 22) was used for the statistical analysis, with the level of significance set to $5 \%(p \leq 0.05)$. The Shapiro-Wilk test was used to determine the normality of the data. Continuous data with normal distribution were compared using the paired Student's $t$-test and the results were expressed as mean and standard deviation values. Nonparametric data were compared using the Wilcoxon test and expressed as median and interquartile range. For the analysis of the percentage contribution of pre- and post-AVD compartments was used ANOVA one way with post-hoc Bonferroni, and the Pearson correlation coefficient between the Glittre-ADL test and $\mathrm{FEV}_{1}$.

The sample size was calculated based on the IC analyzed in the study by Marin et al, ${ }^{19}$ which had a moderate effect size $(\mathrm{d}=0.71)$. Considering an inferential analysis with a nondirectional test, $\alpha=0.05$ level of significance and estimated statistical power of 0.80 , it was determined that a minimum of 22 patients would be needed to document the desired effect.

\section{Results}

Twenty-nine patients were recruited and submitted to evaluation. Four were excluded for not meeting the eligibility criteria (two for being asthmatic, one for knee arthrosis and one for withdrawal). Thus, the final sample was composed of 25 participants (Figure 2).

Table 1 shows demographic, anthropometric and spirometric characteristics of the sample. There was a predominance of the GOLD II classification, individuals within the ideal weight range and similar distribution between the sexes. Three of the 25 patients had been exposed to biomass smoke, 5 were smokers and 17 were ex-smokers, with a mean of $39.2 \pm 31.9$ packs of cigarettes per year.

In Table 2, it can be observed the vital signs and symptoms that were measured at rest and after the Glittre-ADL test. With the exception of diastolic

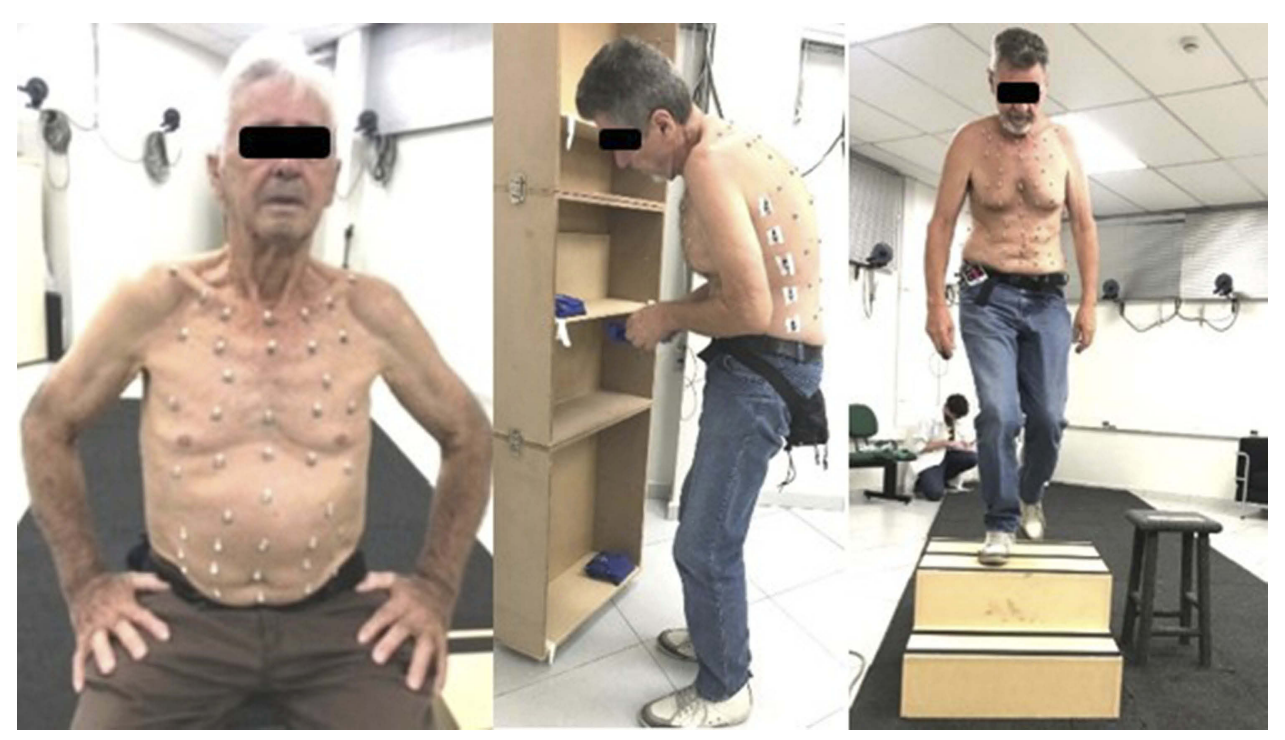

Figure I Individual performing the Glittre-ADL test with the optoelectronic plethysmography (OEP). 


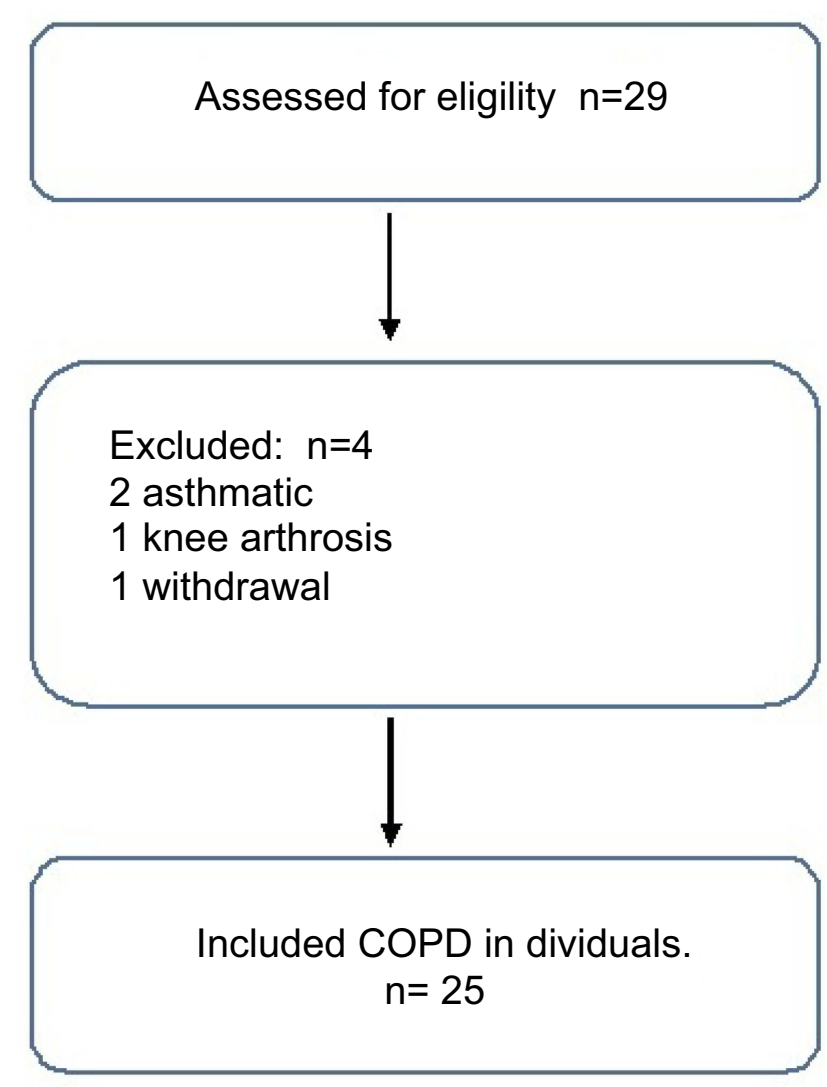

Figure 2 Flowchart on sample selection.

Table I Demographic, anthropometric and spirometric characteristics of the sample

\begin{tabular}{|l|l|}
\hline Variable & $\mathbf{N}=\mathbf{2 5}$ \\
\hline Sex (M/F) & $12 / 13$ \\
Age (years) & $61.9 \pm 10.8$ \\
Weight $(\mathrm{kg})$ & $72.4 \pm 21.6$ \\
Height $(\mathrm{cm})$ & $164.0 \pm 9.7$ \\
BMI (kg/m²) & $25.9 \pm 8.2$ \\
Pack-years & $39.2 \pm 31.9$ \\
GOLD I and II & $8 / 17$ \\
FEV $(\%$ of predicted) & $58.0 \pm 2.1$ \\
FVC (\% of predicted) & $74.2 \pm 18.9$ \\
FEV $/$ /FVC (\%) & $67,12 \pm 10,5$ \\
MVV (\% of predicted) & $55.9 \pm 31.7$ \\
\hline
\end{tabular}

Abbreviation: BMI, body mass index.

blood pressure, significant increases were found in the vital signs before and after exercise (Table 2).

The findings demonstrated the physiological effects of moderate (sub-maximum) exercise. These effects were confirmed by the HR, which remained significantly lower than the predicted maximum HR (Table 3 ).
Table 2 Vital signs and symptoms before and after Glittre-ADL test

\begin{tabular}{|l|l|l|l|}
\hline Variables & Pre-ADL & Post-ADL & $\boldsymbol{p}$ \\
\hline $\mathrm{SpO}_{2}(\%)$ & $94.9 \pm 2.0$ & $91.2 \pm 4.7$ & $0.00 I^{*}$ \\
$R R(\mathrm{rpm})$ & $20.7 \pm 4.6$ & $26.4 \pm 4.1$ & $0.00 I^{*}$ \\
$\mathrm{HR}(\mathrm{bpm})$ & $77.3 \pm 13.8$ & $107.7 \pm 17.4$ & $0.00 I^{*}$ \\
Borg (dyspnea) & $0.0(0.0-0.0)$ & $1.0(1.0-2.5)$ & $0.001^{\dagger}$ \\
Borg (lower limb) & $0.0(0.0-0.0)$ & $0.0(0.0-2.0)$ & $0.002^{\dagger}$ \\
$\mathrm{SBP}(\mathrm{mmHg})$ & $120(1 \mathrm{I}-130)$ & $140(140-150)$ & $0.001^{\dagger}$ \\
$\mathrm{DBP}(\mathrm{mmHg})$ & $90(80-90)$ & $90(80-90)$ & $0.58 \mathrm{I}^{\dagger}$ \\
\hline
\end{tabular}

Notes: *Significant difference ( $p \leq 0.05$, Student's $t$-test); ${ }^{\dagger}$ Significant difference ( $p \leq 0.05$, Wilcoxon test).

Abbreviations: $\mathrm{SpO}_{2}$, peripheral oxygen saturation; RR, respiratory rate; $H R$, heart rate; Borg dyspnea, classification of subjective perception of respiratory effort; Borg lower limb, classification of subjective perception of lower limb exertion; SBP, systolic blood pressure; DBP, diastolic blood pressure.

Table 3 Heart rate and time required to complete Glittre-ADL test

\begin{tabular}{|l|l|l|l|}
\hline $\begin{array}{l}\text { Predicted } \\
\text { max HR }\end{array}$ & $\begin{array}{l}\text { HR after } \\
\text { ADL }\end{array}$ & \% of pred. max & $\boldsymbol{P}$ \\
\hline $163.7 \pm 7.6$ & $107.7 \pm 17.4$ & HR 66 & $0.00 I^{*}$ \\
\hline $\begin{array}{l}\text { Predicted time } \\
\text { of Glittre test }\end{array}$ & $\begin{array}{l}\text { Observed time } \\
\text { of Glittre test }\end{array}$ & $\begin{array}{l}\text { \% of predicted time } \\
\text { of Glittre test }\end{array}$ & $P$ \\
\hline $3.03 \pm 0.14$ & $5.13 \pm 0.42$ & 69 & $0.00 I^{*}$ \\
\hline
\end{tabular}

Note: *Significant difference ( $p \leq 0.05$, paired Student's $t$-test).

Abbreviations: Max HR, maximum heart rate; \% of pred; max HR, percentage of predicted maximum heart rate.

As observed time required to execute the Glittre-ADL test was significantly longer than the predicted time (Table 3 ) and considering the severity of COPD is given by the GOLD classification taking $\mathrm{FEV}_{1}$ into account, the decision was made to perform a correlation analysis of these variables. However, Pearson's test revealed no significant correlation between the time required to complete the Glittre-ADL test and $\mathrm{FEV}_{1}(r=$ $-0.378, p=0.06)$.

Regarding the percentage contributions of the thoracoabdominal compartments before and after the Glittre-ADL test, a significant reduction was found in the contribution of the upper thoracic compartment and a significant increase was found in the contribution of the abdominal compartment after the test. In contrast, no difference was found in the contribution of the lower thoracic compartment (Figure 3).

Since the sample was composed of patients with COPD classified as GOLD I and GOLD II, the decision was made to analyze the groups separately. The results remained similar to those found for the overall sample, with a predominance of the contribution of the abdominal compartment. 


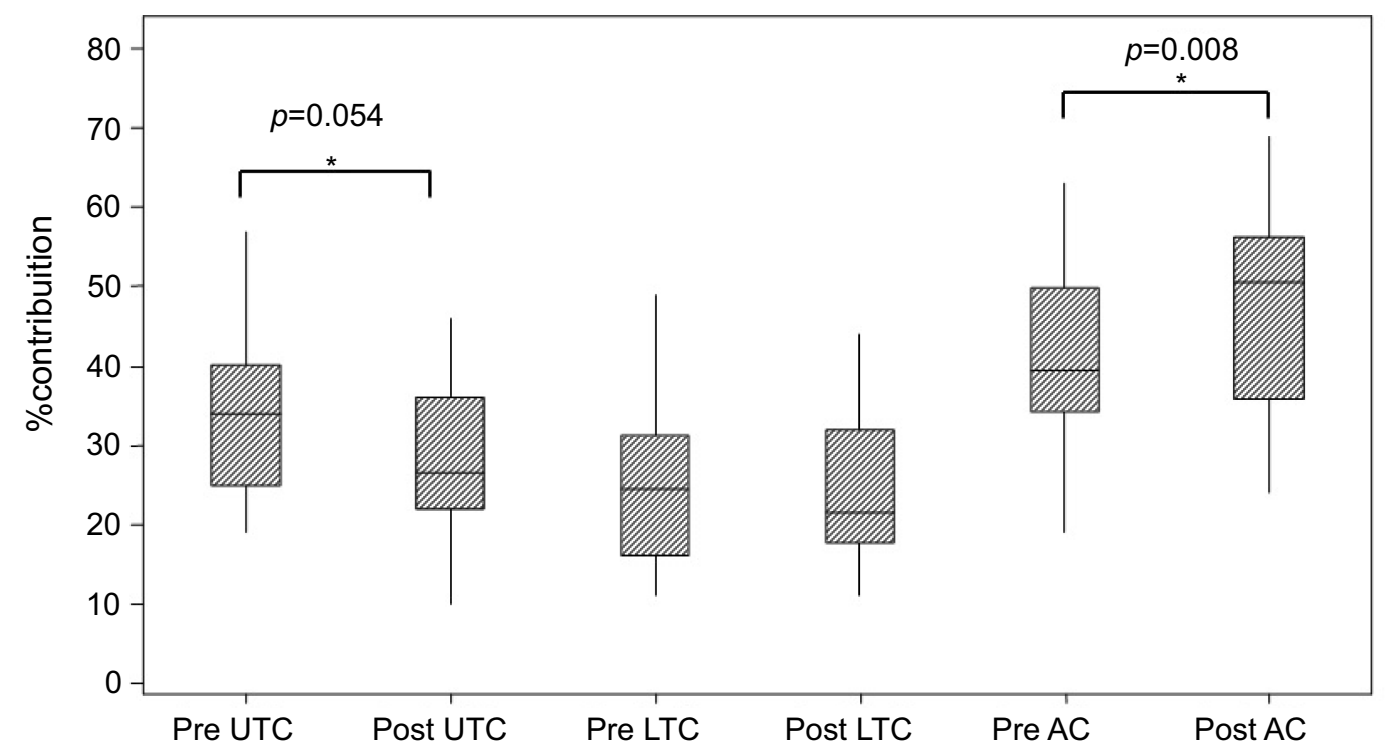

Figure 3 Percentage contributions of thoracoabdominal compartments to respiratory movements before (at rest) and after Glittre-ADL test. * Significant difference ( $p \leq 0.05$, Student's $t$-test).

Abbreviations: UTC, upper thoracic compartment; LTC, lower thoracic compartment; AC, abdominal compartment.

Table 4 Components of vital capacity obtained by spirometry before and after Glittre-ADL test

\begin{tabular}{|l|l|l|l|}
\hline Volumes & Pre ADL & Post ADL & $\boldsymbol{p}$ \\
\hline VC (\%) & $77(72.0-93.0)$ & $82(74.0-106)$ & 0.148 \\
$T V(\mathrm{~mL})$ & $0.72 \pm 0.15$ & $0.76 \pm 0.12$ & 0.260 \\
$I R V(\mathrm{~mL})$ & $1.28 \pm 0.61$ & $1.2 \pm 0.64$ & 0.822 \\
$E R V(\mathrm{~mL})$ & $0.4(0.3-0.6)$ & $0.6(0.3-1.5)$ & $0.002^{\dagger}$ \\
$E R V(\%)$ & $0.59 \pm 0.48$ & $0.87 \pm 0.6$ & 0.006 \\
$I C(\%)$ & $81.0(62.5-92.0)$ & $72(59.5-86.5)$ & $0.040^{\dagger}$ \\
$I C(\mathrm{~mL})$ & $77.1 \pm 15.9$ & $69.8 \pm 22.7$ & 0.076 \\
\hline
\end{tabular}

Note: ${ }^{\dagger}$ Significant difference $(p \leq 0.05$, Wilcoxon test).

Abbreviations: VC, vital capacity; TV, tidal volume; IRV, inspiratory reserve volume; ERV, expiratory reserve volume; IC, inspiratory capacity.

To understand the possible spirometric changes due to the exercises simulating activities of daily living, particularly whether or not DH occurred, vital capacity (VC) was measured before and after the Glittre-ADL test considering the different components of $\mathrm{VC}$ : tidal volume, inspiratory reserve volume, ERV and IC (Table 4).

After the Glittre-ADL test, there was a significant reduction in IC and a significant increase in ERV. These findings indicate a tendency toward DH (Table 4).

\section{Discussion}

The main results of this study showed that after the GlittreADL test there was a reduction in the percentage of contribution of the upper thoracic compartment and a significant increase in the percentage of abdominal compartment, with a reduction in IC and an increase in ERV.

Patients with COPD have a limitation in the activities of daily living, especially those involving the upper limbs, as they cause increased ventilatory demand and $\mathrm{DH}^{3,19,20}$ The present study evaluated the acute effects of the GlittreADL test, which is one of the field tests that most closely resemble activities of daily living, and include walking and arm movements. ${ }^{18}$

The physiological responses of subjects with COPD during the course of the Glittre ADL test have been evaluated. ${ }^{21,22}$ The present study showed that this test has activities that were able to cause sufficient physical effort to lead to a change in HR. Maximum HR after the test was lower than the predicted value, but the physical effort was enough to cause a change in HR, albeit at only a moderate threshold, perhaps due to the fact that the participants were classified as GOLD I and II.

Souza et $\mathrm{al}^{21}$ evaluated 70 individuals with COPD and found significant physiological changes for all vital signs collected after the Glittre-ADL test in a similar manner among the different groups (GOLD I, II and III), as occurred in the present investigation. Karloh et $\mathrm{al}^{22}$ found similar cardiovascular and ventilatory responses between the Glittre-ADL test and Six-Minute Walk Test, with a slightly higher $\mathrm{VO}_{2}$ on the Glittre-ADL test. The authors attribute this difference to a likely greater metabolic uptake during the activity involving the movement of 
objects from one shelf to another, which is the task on the Glittre-ADL test on which the patients reported greater fatigue and dyspnea.

The performance in this test is related to the severity of the disease, ${ }^{18}$ however, in the present study there was no correlation between $\mathrm{FEV}_{1}$ and its execution time. This may have occurred because the sample was composed of individuals with mild to moderate COPD, as well as by the sample size itself, which may not have been enough to show this relationship.

In the analysis of the spirometric data, beside the obstruction evidenced by the $\mathrm{FEV}_{1}$ and $\mathrm{FEV}_{1} / \mathrm{FVC}$ ratio, the reduction in IC and increase in ERV after the test may be mechanical indicators of the occurrence of $\mathrm{DH}$ during the execution of the Glittre-ADL test.

We do not know of any studies that evaluated hyperinflation after the Glittre-ADL test, however in a study involving patients with COPD performing ADL exercises, Velloso et $\mathrm{al}^{4}$ found an increase in expiratory volume with an increase in respiratory rate when the upper arms were raised, but with $\mathrm{DH}$ and a reduction in $\mathrm{IC}$, which is in agreement with the present findings.

According to Scauser et al, ${ }^{6}$ who evaluated DH after activities of daily living in patients with COPD, tidal volume increases minimally when these patients raise the upper limbs, as they breathe higher pulmonary volumes and the additional increase in volume results in a disproportional reduction in dynamic compliance as well as increases in the inspiratory muscle load and respiratory work.

One way for patients with COPD to increase their maximum ventilation when raising the upper limbs is to increase the respiratory rate, since the total pulmonary capacity is not altered with exercise. ${ }^{23}$ However, the premature termination of expiration caused by the rapid respiratory rate further increases air trapping and reduces IC. ${ }^{4,24}$

Regarding the mechanical changes in the thoracoabdominal compartments, the main findings after the GlittreADL test were a significant increase in expiratory volume, a significant reduction in the contribution of the upper thoracic compartment and a significant increase in the contribution of the abdominal compartment.

It was expected that with $\mathrm{DH}$ the accessory muscles would be more recruited ${ }^{5}$ however, some reasons might explain these discrepant results. First it could be the type of exercise as the participants performed multiple activities involving sitting and standing up from a chair, walking, going up and down stairs and moving objects, ${ }^{18}$ the duration and workload of the test; and second the severity of the disease as assessed by levels of airway obstruction and hyperinflation, since higher degrees of hyperinflation occur in more severe patients and mild to moderate COPD patients were assessed. ${ }^{25}$ The finding can reflect the ability of the expiratory muscles to deflate the abdomen at this stage of the disease. ${ }^{26}$

No significant change was found in the lower thoracic compartment. According to some authors, the efficiency of the diaphragm with regard to expanding the lower thoracic compartment may be diminished in individuals with COPD. When taking into account the insertions of the diaphragm, the lower thoracic compartment can be understood as a fixating compartment of respiratory movement. ${ }^{27}$ There may be an increase in the recruitment and activation of non-diaphragmatic inspiratory muscles to compensate for this situation, which is understood as a mechanical disadvantage, since airway obstruction leads to a lowering of the diaphragm domes, which decreases the efficiency of this muscle. ${ }^{16,23}$ The present findings lend support to these statements, as we found a greater contribution of the abdominal compartment, although without a significant increase in tidal volume.

So, it was demonstrated the occurrence of a change in thoracoabdominal kinetics, especially regarding the percentage contribution of the abdominal compartment, as an acute effect of exercise simulating activities of daily living, demonstrated by the OEP results. These findings, together with the reduction in IC and increase in ERV following the Glittre-ADL test, suggest the occurrence of post-exercise $\mathrm{DH}$, even in patients with mild to moderate COPD. The findings also show that the Glittre-ADL test is reproducible for this evaluation.

The limitations of this study are related to the absence of patients with GOLD III, who are those who usually present more hyperinflation, and who could explain the findings better, as well as the absence of comparison of exercises with isolated follow-up, such as upper limbs and lower limbs with ADL.

\section{Acknowledgements}

The authors would like to acknowledge grateful to all patients who agreed to participate in this study and to the Respiratory Functional Evaluation Laboratories (LARESP) and the Multidisciplinary Laboratory for the Analysis of the Human Movement (LMAMH), from Postgraduate Program of the Rehabilitation's Sciences in UNINOVE. 


\section{Disclosure}

The authors report no conflicts of interest in this work.

\section{References}

1. Jardim JR, Oliveira JA, Nascimento O. II Consenso Brasileiro de DPOC. J Bras Pneumol. 2004;30:S1-S42.

2. Dourado VZ, Tanni SE, Vale SA, Faganello MM, Sanchez FF, Godoy I. Systemic manifestations in chronic obstructive pulmonary disease. J Bras Pneumol. 2006;32:161-171.

3. Azevedo KRS. Pulmonary functional evaluation in COPD. Pulmão RJ. 2013;22(2):24-29.

4. Velloso M, Stella SG, Cendon S, Silva AC, Jardim JR. Metabolic and ventilatory parameters of four activities of daily living accomplished with arms in COPD patients. Chest. 2003;123:1047-1053.

5. O'Donnel DE, Webb KA. Dinamic hyperinflation and exercise intolerance in chronic obstructive pulmonar disease. Am J Respir Crit Care Med. 2001;164:770-777. doi:10.1164/ajrccm.164.5.2012122

6. Sclauser IM, Pessoa BV, Parreira VF, Lorenzo VAP, Reis MAS, Costa D. Analysis of dynamic pulmonary hyperinflation (hd) after daily life activity in patients with chronic obstructive pulmonary disease. Rev Bras Fisioter. 2007;11(6):469-474.

7. Silva SC, Nogueira FR, Porto EF, et al. Dynamic hyperinflation during activities of daily living in COPD patients. Chr Resp Dis. 2015;12(3):189-196. doi:10.1177/1479972315576143

8. Hellebrandová L, Chlumský J, Vostatek P, Novák D, Rýznarová Z, Bunc V. Airflow limitation is accompanied by diaphragm dysfunction. Physiol Rev. 2016;65:469-479.

9. Parreira VF, Vieira DSR, Myrrha MAC, Pessoa IMBS, Lage SM, Britto RR. Optoelectronic plethysmography: a review of the literature. Rev Bras Fisioter. 2012;16(6):439-453.

10. Fernandes-Andrade AA, Britto RR, Soares DMC, Velloso M, Pereira DAG. Evaluation of the Glittre-ADL test as an instrument for classifying functional capacity of individuals with cardiovascular diseases. Braz J Phys Ther. 2017;21(5):321-328. doi:10.1016/j.bjpt.2017.06.001

11. Skumlien S, Hagelund T, Bjørtuft O, Ryg MS. A field test of functional status as performance of activities of daily living in COPD patients. Respir Med. 2006;100(2):316-323. doi:10.1016/j.rmed.2005.04.022

12. José A, Dal Corso S. Reproducibility of the six-minute walk test and Glittre ADL-test in patients hospitalized for acute and exacerbated chronic lung disease. Braz J Phys Ther. 2015;19(3):235-242. doi:10.1590/bjpt-rbf.2014.0092

13. American thoracic society statement standardization of spirometry - update. Am Rev Respir Dis. 1987;136:1285-1298. doi:10.1164/ajrccm/136.5.1285

14. Pereira CAC, Sato T, Rodrigues SC. New reference values for forced spirometry in white adults in Brazil. J Bras Pneumol. 2007;33 (4):397-406. doi:10.1590/S1806-37132007000400008

15. Aliverti A, Pedotti A. Opto-electronic plethysmography. Monaldi Arch Chest Dis. 2003;59(1):12-16.
16. Aliverti A, Quaranta M, Chakrabarti B, Albuquerque ALP, Calverley PM. Paradoxical movement of the lower rib cage at rest and during exercise in COPD patients. Eur Respir J. 2009;33:49-60. doi:10.1183/09031936.00141607

17. Tufanin A, Gerson FSG, Tisi GR, Tufik S, Mello MT, Nascimento JAR. Cardiac, ventilatory, and metabolic adjustments in chronic obstructive pulmonary disease patients during the performance of Glittre activities of daily living test. Chr Resp Dis. 2014;11(4):247-255. doi:10.1177/1479972314552805

18. Reis CM, Karloh M, Fonseca FR, Biscaro RRM, Mazo GZ, Mayer AF. Avaliação funcional: equações de referência para o teste de Glittre Activities of Daily Living. J Bras Pneumol. 2018;44 (5):370-377. doi:10.1590/S1806-37562017000000118

19. Marin JM, Carrizo SJ, Gascon M, Sanchez A, Gallego B, Celli BR. Inspiratory capacity, dynamic hyperinflation, breathlessness, and exercise performance during the 6 min-walk test in chronic obstructive pulmonary disease. Am J Respir Crit Care Med. 2001;163 (6):1395-1399. doi:10.1164/ajrccm.163.6.2003172

20. Cooper CB. The connection between chronic obstructive pulmonary disease symptoms and hyperinflation and its impact on exercise and function. Am J Med. 2006;119(10A):S21-S31. doi:10.1016/j. amjmed.2006.08.004

21. Souza GF, Moreira GL, Tufanin A, et al. Physiological requirements to perform the glittre activities of daily living test by subjects with mild-to-severe. Resp Care. 2017;62(8):1049-1057. doi:10.4187/ respcare. 05113

22. Karloh M, Karsten M, Pissaia FV, Araujo CLP, Mayer AF. Physiological responses to the Glittre-ADL test in patients with chronic obstructive pulmonary disease. $J$ Rehabil Med. 2014;46:88-94. doi:10.2340/16501977-1217

23. Chihara K, Kenyon CM, Macklem PT. Human rib cage distortability. J Appl Physiol. 1996;81(1):437-447. doi:10.1152/ jappl.1996.81.1.437

24. Aliverti A, Iandelli I, Duranti R, et al. Respiratory muscle dynamics and control during exercise with externally imposed expiratory flow limitation. J Appl Physiol. 2002;92(5):1953-1963. doi:10.1152/ japplphysiol.01222.2000

25. Castro AAM, Kümpel C, Rangueri RC, et al. Daily activities are sufficient to induce dynamic pulmonar hyperinflation and dyspnea in chronic obstructive pulmonar disease patients. Clinics. 2012;67 (4):319-325. doi:10.6061/clinics/2012(04)04

26. Romagnoli I, Gorini M, Gigliotti F, et al. Chest wall kinematics and respiratory muscle action and dyspnea during arm vs. leg exercise in humans. Acta Physiol. 2006;188(1):63-73. doi:10.1111/j.17481716.2006.01607.x

27. Casanova C, Cote CG, Marin JM, et al. The 6-min walking distance: long-term follow up in patients with COPD. Eur Respir J. 2007;29:535-540. doi:10.1183/09031936.00071506
The International Journal of COPD is an international, peer-reviewed journal of therapeutics and pharmacology focusing on concise rapid reporting of clinical studies and reviews in COPD. Special focus is given to the pathophysiological processes underlying the disease, intervention programs, patient focused education, and self management protocols. This journal is indexed on PubMed Central, MedLine and CAS. The manuscript management system is completely online and includes a very quick and fair peer-review system, which is all easy to use. Visit http://www.dovepress.com/testimonials.php to read real quotes from published authors. 